\title{
The Impact of Our High Impact Factor
}

\section{Jong S. Kim}

Editor in Chief, Journal of Stroke

I am delighted to inform you that the Journal of Stroke's (JoS) impact factor has strikingly increased from 5.57 last year to 7.47 , which is the highest among all international journals devoted to stroke research. I sincerely thank all the members of the editorial team, including Ji Hoe, Keun-Sik, Dong-Eog, Edip, Jin Soo, Joonsang, and So-Yeon, for their hard work. Such tremendous success could not have been achieved without their dedication. I am also indebted to the contributors who submitted excellent research articles, researchers who willingly cited JoS papers in their works, and reviewers who generously spent their time reviewing the submitted articles. Apart from South Korea, the USA, China, Taiwan, Germany, France, Spain, India, the Netherlands, and Australia were among the top 10 countries that submitted articles to JoS last year. Consequently, JoS, which is an official journal of the Korean Stroke Society, has now be- come sufficiently internationalized. Although impact factor is not the only marker of a journal's quality, its high value has convinced us that our journal is significantly promoting the dissemination of scientific knowledge and impacting the development of stroke research globally.

Cheers.

\section{Correspondence: Jong S. Kim}

Department of Neurology, Asan Medical Center, University of Ulsan College of Medicine, 88 Olympic-ro 43-gil, Songpa-gu, Seoul 05505, Korea

Tel: +82-2-3010-3442

Fax: +82-2-474-4691

E-mail: jongskim@amc.seoul.kr

https://orcid.org/0000-0002-3999-4992

The author has no financial conflicts of interest. 